\title{
Beef Production in the Southwestern United States: Strategies Toward Sustainability
}

\author{
Sheri Spiegal ${ }^{1 *}$, Andres F. Cibils ${ }^{2}$, Brandon T. Bestelmeyer ${ }^{1}$, Jean L. Steiner ${ }^{2}$, \\ Richard E. Estell ${ }^{1}$, David W. Archer ${ }^{3}$, Brent W. Auvermann ${ }^{4}$, Stephanie V. Bestelmeyer ${ }^{5}$, \\ Laura E. Boucheron ${ }^{6}$, Huiping Cao ${ }^{7}$, Andrew R. Cox ${ }^{8}$, Daniel Devlin ${ }^{9}$, Glenn C. Duff ${ }^{2,10}$, \\ Kristy K. Ehlers ${ }^{11}$, Emile H. Elias ${ }^{1,12}$, Craig A. Gifford ${ }^{13}$, Alfredo L. Gonzalez ${ }^{1}$, \\ John P. Holland ${ }^{14}$, Jenny S. Jennings ${ }^{4}$, Ann M. Marshall ${ }^{11}$, David I. McCracken ${ }^{14}$, \\ Matthew M. Mclntosh ${ }^{2}$, Rhonda Miller ${ }^{15}$, Mark Musumba ${ }^{2}$, Robert Paulin ${ }^{16}$, \\ Sara E. Place ${ }^{17}$, Matthew Redd ${ }^{18}$, C. Alan Rotz ${ }^{19}$, Cindy Tolle ${ }^{20}$ and Anthony Waterhouse ${ }^{14}$
}

\section{OPEN ACCESS}

Edited by:

Mark A. Drummond,

United States Geological Survey (USGS), United States

Reviewed by:

Christopher Laingen, Eastern Illinois University,

United States

Jennifer Tucker,

The University of Georgia,

United States

*Correspondence: Sheri Spiegal

sheri.spiegal@usda.gov

Specialty section:

This article was submitted to Land, Livelihoods and Food Security,

a section of the journal

Frontiers in Sustainable Food Systems

Received: 30 August 2019

Accepted: 25 June 2020

Published: 19 August 2020

Citation:

Spiegal S, Cibils AF, Bestelmeyer BT, Steiner JL, Estell RE, Archer DW, Auvermann BW, Bestelmeyer SV, Boucheron LE, Cao H, Cox AR, Devlin D, Duff GC, Ehlers KK,

Elias EH, Gifford CA, Gonzalez AL, Holland JP, Jennings JS, Marshall AM, McCracken DI, Mclntosh MM Miller R, Musumba M, Paulin R

Place SE, Redd M, Rotz CA, Tolle C and Waterhouse $A$ (2020) Beef Production in the Southwestern United States: Strategies Toward Sustainability

Front. Sustain. Food Syst. 4:114 doi: 10.3389/fsufs. 2020.00114
1 USDA-ARS Jornada Experimental Range, Las Cruces, NM, United States, ${ }^{2}$ Department of Animal and Range Sciences, New Mexico State University, Las Cruces, NM, United States, ${ }^{3}$ USDA-ARS Northern Great Plains Research Laboratory, Mandan, ND, United States, ${ }^{4}$ Texas A\&M AgriLife Research, Amarillo, TX. United States, ${ }^{5}$ Asombro Institute for Science Education, Las Cruces, NM, United States, ${ }^{6}$ Klipsch School of Electrical and Computer Engineering, New Mexico State University, Las Cruces, NM, United States, ${ }^{7}$ Department of Computer Science, New Mexico State University, Las Cruces, NM, United States, ${ }^{8}$ Chihuahuan Desert Rangeland Research Center, New Mexico State University, Las Cruces, NM, United States, ${ }^{9}$ Kansas Center for Agricultural Resources and the Environment \& Kansas Water Resources Institute, Kansas State University, Manhattan, KS, United States, ${ }^{10}$ Clayton Livestock Research Center, New Mexico State University, Las Cruces, NM, United States, ${ }^{11}$ BlueSTEM AgriLearning Center, El Reno, OK, United States, ${ }^{12}$ USDA Southwest Climate Hub, Las Cruces, NM, United States, ${ }^{13}$ Extension Animal Sciences and Natural Resources, New Mexico State University, Las Cruces, NM, United States, ${ }^{14}$ Hill \& Mountain Research Centre, Scotland's Rural College, Perthshire, United Kingdom, ${ }^{15}$ Department of Animal Science, Texas A\&M, College Station, TX, United States, ${ }^{16}$ Corta Madera Ranch, Pine Valley, CA, United States, ${ }^{17}$ ELANCO, Greenfield, IN, United States, ${ }^{18}$ The Nature Conservancy, Dugout Ranch and Canyonlands Research Center, Monticello, UT, United States, ${ }^{19}$ USDA-ARS Pasture Systems and Watershed Management Research Unit, State College, PA, United States, ${ }^{20}$ Evergreen Ranching \& Livestock, Custer, SD, United States

From grazing lands to meat packing, beef production systems in the United States are striving to meet global demands without compromising environmental quality or local profitability. These challenges and opportunities are manifest in four US regions connected ecologically and socially through beef production: the American Southwest, the Ogallala Aquifer region, the Northern Plains, and the Upper Midwestern Corn Belt. Most calves raised on extensive, arid Southwestern ranches are exported to the Ogallala Aquifer region for finishing on grains that are grown either locally on Ogallala Aquifer water or imported from the Upper Midwest. Changes in climate, vegetation, and human demographics threaten the sustainability of the regionally-interconnected system. Heritage cattle genetics, precision ranching, and alternative supply chain options are three strategies that show promise for addressing these sustainability threats, but major knowledge gaps exist. For instance, while environmentally-friendly landscape use by Raramuri Criollo, a heritage cattle type, has been identified in several arid rangeland settings, little is known about their performance in conventional feed yards. While precision agriculture is already prevalent in croplands, less is known about how such technologies can be cost effective in arid rangelands. Moreover, many perceive grass-finishing on rangeland as environmentally friendly and beneficial for local agricultural communities, but tradeoffs involving greenhouse gas emissions, increased rangeland use, and disruption of cattle feeding systems of the Ogallala Aquifer region must be assessed. Here we introduce 
a USDA-NIFA Coordinated Agricultural Project designed to fill these knowledge gaps and advance sustainability of beef production linked to the US Southwest. With a boundary-spanning approach of education, participatory research, and extension, the project is identifying tradeoffs of the three strategies with explicit attention to pericoupling (i.e., socioeconomic and environmental interactions) of regions connected by beef production and full consideration of the coupled ecological and social systems within those regions.

Keywords: Southwestern United States, rangelands, sustainable agricultural systems, Coordinated Agricultural Project, pericoupling framework

\section{INTRODUCTION}

Humans have used livestock grazing to adapt to arid landscapes for millennia (Clutton-Brock, 1989), but as livestock production has become embedded in a complex transnational meat supply chain, new strategies are needed to ensure sustainable production into the future. In the United States, about 25,000 cattle ranches are located in the arid and semi-arid Southwest ${ }^{1}$. These ranches produce $\sim 6 \%$ of the cows that provide calves for the US beef industry, making Southwestern ranching essential not only to local communities, economies, and landscapes, but to the nation's overall beef supply, as well (Havstad et al., 2018; USDANASS, 2020). However, the fragility of the predominant supply chain emanating from the Southwest coupled with increasing heat and drought are threatening the capacity of Southwestern ranchers to produce beef sustainably (Gershunov et al., 2013; Polley et al., 2013; Havstad et al., 2018; McIntosh et al., 2019; Hendrickson, 2020).

Most calves weaned on the cow-calf ranches of the Southwest are exported to the Ogallala Aquifer region ${ }^{2}$ for backgrounding, grain finishing, and meat sales (Johnson and Becker, 2009; Buhnerkempe et al., 2013; Blank et al., 2016). The Ogallala Aquifer region also imports grain from the Upper Midwest ${ }^{3}$ to meet feeding quotas not filled by local feed production (Gottschalk, 2007; Guerrero et al., 2013). Problems in one link of this inter-regional supply chain can compromise resilience of the entire chain. Moreover, interventions designed to solve problems in one region affect, and are affected by, ecological and socioeconomic dynamics in connected regions. Therefore, to foster beef production that is truly sustainable - that is, that satisfies dietary demand, protects environmental quality, and ensures economic security and good quality of life for producers and society (National Research Council, 2010; Kleinman et al., 2018) - we must understand the performance of beef production in multiple realms and in the multiple regions connected by supply and demand (Liu, 2017).

With these goals in mind, three strategies show promise for improving sustainability of beef production originating in the US Southwest and the regions connected to it: heritage

${ }^{1}$ We define the US Southwest as the states of New Mexico, Arizona, Nevada, Utah, California (Figure 1).

${ }^{2}$ We define the Ogallala Aquifer region as parts of Texas, New Mexico, Oklahoma, Kansas, Nebraska, Colorado, Wyoming, and South Dakota (Figure 1).

${ }^{3}$ We define the Upper Midwest as the "Corn Belt" which covers Indiana, Illinois, Iowa, Missouri, eastern Nebraska, and eastern Kansas. cattle genetics, precision ranching, and alternative supply chain options. Here we summarize the major challenges to the sustainability of Southwest beef production, provide rationale for evaluating these three strategies as ways to address the challenges, and report early results of our multi-disciplinary, multi-year approach to understanding the benefits and drawbacks associated with each strategy (Figure 1). Our approach was funded in 2019 as a 5-year Coordinated Agricultural Project (CAP) by the United States Department of Agriculture - National Institute of Food and Agriculture (NIFA-AFRI \#2019-69012-29853, www. swbeef.org). Here we report results of the first year of the "Sustainable Southwest Beef CAP."

\section{SUSTAINABILITY CHALLENGES FOR SOUTHWEST BEEF PRODUCTION}

\section{Sustainability Challenges on Pasture and Ranch Scales}

Similar to other arid landscapes worldwide, range pastures of the American Southwest tend to be large and heterogeneous. Frequent use of particular locations by cattle can result in perennial grass loss (Bestelmeyer et al., 2018), soil degradation (Nash et al., 2003), and increased dust emissions (Baddock et al., 2011) - all of which diminish cattle weight gains (Holechek, 1992). Manipulating fencing, water locations, and timing of use are common approaches to improving livestock distribution in rangelands (Heitschmidt and Taylor, 1991; Owens et al., 1991). These interventions, however, can be cost-prohibitive to establish and maintain in arid systems (Hunt et al., 2007).

High input costs coupled with external market forces contribute to rates of return varying from net losses to only $+3 \%$ on annual investment in the ranches of the American Southwest - significantly lower than the $6 \%$ received by US agriculture on the whole (Torell et al., 2001; USDA-ERS, 2016). Looking ahead, these economic stresses are projected to intensify as the Southwest continues to experience higher temperatures, increasing frequency and intensity of heat waves, and more frequent droughts (Gershunov et al., 2013; Briske et al., 2015; USGCRP, 2017). These novel climate exposures are predicted to affect ecosystems and economics through diminished rangeland carrying capacities, increased site vulnerability to soil degradation, compromised regional feed and pasture forage production, and intensified animal heat stress (Havstad et al., 2018). 


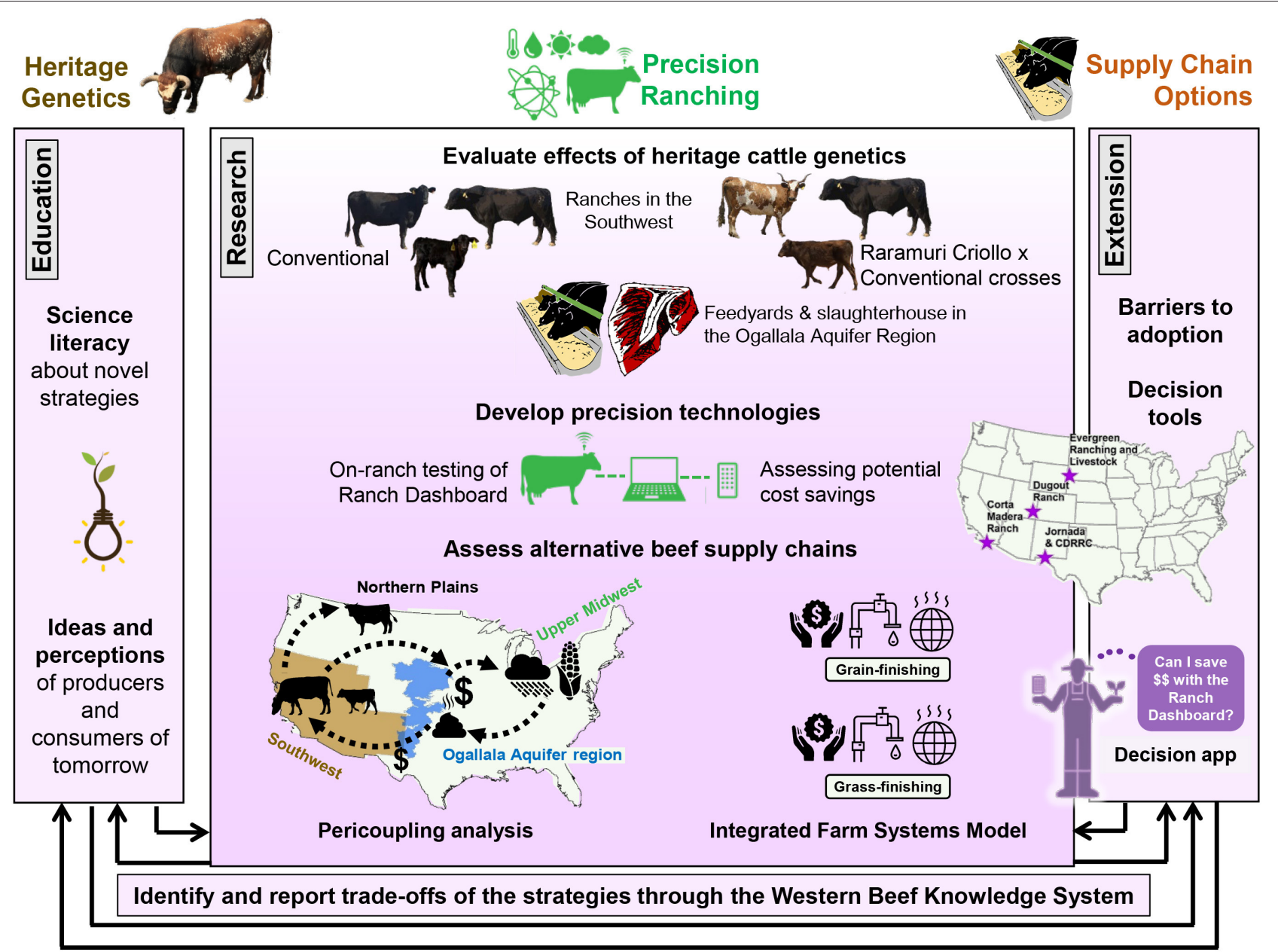

FIGURE 1 | The Sustainable Southwest Beef CAP is investigating three strategies with potential to improve sustainability of beef production originating from the American Southwest, using a boundary-spanning approach of education, participatory research, and extension.

\section{Sustainability Challenges on the Supply Chain Scale}

Looking beyond ranch gates, the specialization and concentration of US beef cattle and cattle feed production has greatly increased efficiency in terms of cost per unit of product of beef (Dimitri et al., 2005; Capper, 2011); however, it has also contributed to a host of environmental, economic, and societal concerns, including compromised environmental quality and quality of life for communities near concentrated feedlot manure (Casey et al., 2006), as well as vulnerabilities in supply chains. For instance, occupancy restrictions in meat processing plants experienced in the spring of 2020 due to COVID-19 have resulted in cattle remaining in feedyards longer, and fewer conventional cuts being available in supermarkets, affecting the ranches upstream (Peel et al., 2020; Texas A\&M, 2020). The lack of typical beef cuts and volume in supermarkets resulted, for many Americans, in expanded interest in the provenance of beef and local beef products (Atkins, 2020; Emmert, 2020; Nagus, 2020). While it is too early to predict long-term effects at the writing of this article, it is possible that investment in alternative, local supply chains may ultimately affect the long-term economic sustainability of conventional grain finishing (Hobbs, 2020).

\section{STRATEGIES TOWARD SUSTAINABILITY: NEW RESEARCH AND EARLY RESULTS}

\section{Heritage Cattle}

The Raramuri Criollo biotype has undergone 500 years of adaptation to the harsh conditions of the Sierra Tarahumara in northern Mexico with minimal genetic influence of improved beef breeds (Estell et al., 2012; Anderson et al., 2015). Based on past research, Raramuri Criollo appear to experience less heat stress on hot summer days (Nyamuryekung'e et al., 2017) and have been anecdotally observed to forage more on low-quality grasses and shrubs than conventional beef breeds (Anderson et al., 2015). In addition, during seasons when green forage is relatively scarce and patchily distributed, Raramuri Criollo have been found to achieve greater distribution than conventional cattle types (Peinetti et al., 2011; Spiegal et al., 2019). 
To date, grass finishing has been the primary option for Southwestern producers raising Raramuri Criollo, which can be finished on grass but get passed over at auctions in the conventional production chain due to color and shape nonconformity (Enyinnaya, 2016; Torell et al., in review). Another option is cross-breeding the heritage type with beef breeds used conventionally, thereby maintaining the potential economic and environmental benefits of Raramuri Criollo cows while producing more widely marketable offspring (Martínez-Cordova et al., 2014; Mcintosh et al., 2018).

While grass finishing and grain-finishing cattle with Raramuri Criollo genetics show promise for economic and environmental sustainability, especially under warmer and drier conditions, more information is needed before adoption of Raramuri Criollo genetics can be widely recommended. To fill these information gaps, a long-term breed comparison study was initiated in March 2020 on the New Mexico State University (NMSU) Chihuahuan Desert Rangeland Research Center (CDRRC) in Las Cruces, New Mexico. Four large pastures were dedicated to the respective cow-calf herds - two pastures for a heritage herd, and two for a conventional Brangus herd. External inputs and outputs are being quantified to assess differences in ranch total factor productivity (Ramankutty et al., 2018) between herds, and vegetation and soils are being monitoring to assess the ecological effects. To understand the processes driving production and ecological outcomes, cattle movements are being monitored in real time (see below), and costs and returns are being measured, including supplement intake, percent calf crop, and kilograms of calf weaned.

The feedlot and finishing performance will be compared between the heritage crossbred calves and conventional beef calves at research facilities in the Ogallala Aquifer region. Calves for this component of the study are being raised on cooperating ranches in southern New Mexico, southeastern California, and southeastern Utah (stars in Figure 1). The first calf crop is scheduled to be transported to Clayton, New Mexico for wheat pasture backgrounding and eventual finishing at Clayton, New Mexico, and Texas A\&M Agrilife Research facilities in Bushland, Texas in fall 2020, and repeated the following 2 years. Slaughtered cattle will be subjected to beef quality tests including consumer taste panels at Texas A\&M University in College Station, Texas in 2021, 2022, and 2023.

This breed comparison leverages one of 18 coordinated experiments in the Long-Term Agroecosystem Research (LTAR) network Common Experiment, contributing to a national assessment of the benefits and drawbacks of adopting "aspirational" management approaches on farms and ranches nationwide (Spiegal et al., 2018). This experiment is also part of an international network of long term grazing studies comparing the environmental footprint of Criollo vs. improved beef breeds at sites in Mexico and Argentina.

\section{Precision Ranching}

Sensor-driven precision farming, already mainstream in intensive animal agriculture systems (Neethirajan, 2017), can also help ranchers in the warming and drying American Southwest make rapid decisions to sustain animal health and forage resources. Real-time analysis of shifts in animal movement patterns associated with declining forage, inadequate or faulty water supply, birth, or predation helps ranchers to intervene rapidly, effectively providing a type of early warning system addressing multiple sustainability problems.

Importantly, these technologies can help reduce economic and environmental costs of ranching in extensive, arid lands. Based on calculations for the $780-\mathrm{km}^{2}$ USDA-ARS Jornada Experimental Range, wireless sensors indicating water levels in troughs could save $388-478 \mathrm{~h}$ of driving time and 742-956 gallons of fuel, which translates into $\$ 7,800-\$ 10,000$ in annual cost savings, 6.6-8.5 metric tons of avoided $\mathrm{CO}_{2}$ emissions, and more time for pursuing other endeavors. On the other hand, investments in the system such as installation, maintenance, and time spent learning to use the technology can reduce overall cost-effectiveness of adoption.

To investigate the potential of these technologies in extensive arid landscapes, we are developing a precision ranching system able to log, transmit, and analyze animal, weather, and water sensor data in real time via a long-range, low power wireless area network (LoRa WAN), to be tested at five participating ranches (Figure 1). Cost inputs and savings from this technology will be assessed via enterprise budgets (Torell et al., 2014), and a survey instrument will be used to determine user perceptions regarding the usefulness of all aspects of system implementation. With this understanding of cost savings and feedback from participating ranchers, a market-ready product should be available within 6 years.

During the first year of the project, we built a pilot model and are testing it at the NMSU CDRRC, where the long-term breed comparison study was initiated. The GPS collars, watering tank, and rainfall sensors have been collecting data since March 2020 (Supplement 1). Initial testing and calibration of components of the precision ranching system at CDRRC is allowing us to gauge its usefulness and is helping our team identify and carefully document potential challenges of using LoRa WAN on extensive cattle ranches with sparse communication networks. Understanding these technological hurdles will be critically important as we roll out the precision ranching system on cooperating commercial ranches in the near future.

\section{Supply Chain Options}

Amid concerns about food safety and environmental impacts of beef supply chains, the market share for alternative beef products - natural, certified organic, grass-fed - has been growing in recent decades (Tonsor et al., 2009; Mathews and Johnson, 2013; Food Marketing Institute, 2017), and societal interest in locallysourced food appears to be growing rapidly during the ongoing COVID-19 pandemic. Thus, ranchers who grass-finish Raramuri Criollo cattle are part of a larger community in the American Southwest that has adopted grass finishing for a variety of reasons (Barnes, 2011).

During the past year of engaging with Southwestern producers who grass finish cattle, we have come to identify two main approaches: (1) finishing locally on arid ranches, and (2) exporting weaned calves to the Northern Plains ${ }^{4}$ (the

${ }^{4}$ We define the Northern Plains as North Dakota, South Dakota, Minnesota, Iowa, and Nebraska. 
"Follow the Green" production system). Much is unknown about the rate of adoption of these approaches, their ecological and economic outcomes, or how those outcomes compare with those of grain finishing systems - especially as the Ogallala Aquifer region's backgrounding and feedlot industries face threats of aquifer depletion (McGuire, 2017) and the expanding impacts of the COVID-19 pandemic (Hendrickson, 2020). Therefore, we are working to create a knowledge base for producers, consumers, regional planners, and policy makers involved with Southwest beef production so they can compare grass finishing vs. grain finishing under various scenarios of change. Our primary analytical tools are the Integrated Farm System Model (IFSM; Rotz et al., 2019) and a multi-regional "pericoupling" analysis (Liu, 2017).

The IFSM uses production inputs in the farms and ranches of a given supply chain to estimate the environmental and economic outcomes of that supply chain (including energy use; carbon, phosphorus, and reactive nitrogen footprints; water consumption; production costs; and net returns). We are using IFSM to compare economic and environmental outcomes in six supply chains: Follow the Green with and without Raramuri Criollo, Grass-Finishing in the Southwest with and without Raramuri Criollo, and GrainFinishing in the Ogallala Aquifer Region with and without Raramuri Criollo. We are gathering information on inputs from five ranchers and two feedyard operators formally participating in project research, as well as from other producers engaged through the CAP's extension efforts (see below). Ultimately the simulated environmental and economic effects will provide a measure of the long-term sustainability of the six supply chains, so that tradeoffs can be quantified and compared.

All six production systems being simulated in the IFSM originate with calves born on Southwestern ranches. The weaned calves are then exported to other regions (Follow the Green, Grain-Finishing), or are held back from those regions (Grass-Finishing in the Southwest). Given these inter-regional connections, we aim to understand how dynamics in one region affect the dynamics of the others, and vice versa. To that end, we are conducting a "pericoupling" analysis (Liu, 2017) to characterize the socioeconomic and environmental interactions among the regional systems linked via beef production under both the current system and a plausible near-future scenario (da Silva et al., 2019). Using the pericoupling framework, we are addressing the following questions about the connected regions under both the current and future scenarios (Table 1):

1. What are the flows of resources among four regions connected through beef production (the Southwest, Ogallala Aquifer region, Upper Midwest, and Northern Plains)?

2. What agents bring forth the connections (pericouplings) between the regions?

3. What are the causes of the pericouplings between the regions?

4. What are the major effects of the pericouplings on each region?

During the past year, we have built our pericoupling database with agro-economic datasets that span national, state, and regional levels, as well as results from IFSM simulations, and information from our integrated extension and education activities. Preliminary results are in Table 1.

TABLE 1 | Preliminary results of a pericoupling analysis to assess linkages of four regions affected by beef production in the American Southwest, under the current system and a plausible near-future scenario.

Scenario Current Future

Flows $\quad$ Weaned calves: Almost all calves weaned on Southwestern ranches are exported to the Ogallala Aquifer region for finishinga. Feed grain: A large proportion of the grains used in finishing in the Ogallala Aquifer region are imported from the Upper Midwest. Cattle payments: Ogallala Aquifer region pays the Southwest via calf purchases. Manure nutrients: The Ogallala Aquifer region takes responsibility for managing manure nutrients of calves imported from the Southwest.

Agents

Causes

-Ranchers, brokers, vertically integrated feedyards/packers, major beef Consumers' sustained demand for marbled beef. Location of major meat packers and vertical integration of animal production in US. Economies of scale for grain finishing.

Effects "Brittle" food system. In Ogallala Aquifer region: Calves imported from the Southwest support employment in backgrounding and grain-finishing industries. Use of aquifer water for backgrounding and finishing calves from the Southwest. Declining water table levels. In Upper Midwest: The Ogallala Aquifer region is a market for grain.

\section{Future}

Weaned calves: Half of the calves weaned on Southwestern ranches are exported to the Ogallala Aquifer region for grain finishing, a quarter are exported to the Northern Plains for grass finishing, and a quarter are retained in the Southwest for grass finishing. Feed grain: Amount imported by the Ogallala Aquifer region from the Upper Midwest decreases. Cattle payments: Ogallala Aquifer region and Northern Plains pay the Southwest via calf purchases. Money received via calf purchases is retained in the Southwest. Manure nutrients: The Ogallala Aquifer region and Northern Plains are responsible for managing manure nutrients for imported calves; more manure nutrients are retained on Southwestern rangelands.

f retailers, policy-makers, consumers, niche marketing cooperativesConsumer concerns about grain-finishing supply chain; increased and sustained demand for alternatives. Continued social distancing as experienced in spring 2020. Reduced availability of Ogallala Aquifer water for backgrounding and feedlots. Input cost savings and/or government cost-sharing via heritage genetics and precision ranching.

In Ogallala Aquifer region: Reductions in: imported grains, imported beef cattle manure loads, employment in backgrounding and grain-finishing industries, aquifer water use. In the Southwest: Increases in: range use, hay demand, local revenue, opportunities for niche marketing. Longer methanogenic rumination. In Upper Midwest: Grain market disruption. In Northern Plains: Increased range use and possibly increased demand for feeder calves to utilize Ogallala Aquifer region packing quotas.

\footnotetext{
a See Supplement 2 for initial data analysis to estimate cattle flows from the US Southwest to the Ogallala Aquifer region.
} 


\section{BOUNDARY-SPANNING APPROACH}

We designed the Sustainable Southwest Beef CAP to span boundaries between science and decision-making in order to improve actions in both realms (sensu Bednarek et al., 2018). A central pillar is participatory research: All research is being conducted at least in part on commercial ranches, with direct involvement of ranch operators. This involvement, from study design to execution to data interpretation, is ensuring tight linkages between science and real-world challenges and opportunities in Southwestern beef production. The boundaryspanning approach was adopted, in part, to ensure a realistic understanding of opportunities for, and barriers to, adoption of the strategies under investigation.

To understand more about the potential for adoption of the strategies under investigation, during the past year, knowledge co-production/extension partners in the Sustainable Southwest Beef CAP - from New Mexico State University, the USDA Southwest Climate Hub, and Texas A\&M AgriLife - engaged with producers from the Southwest and the regions pericoupled to the Southwest through beef production. Central tools have been on-ranch demonstrations, in-person events, podcasts, and surveys. For instance, the project team hosted an event for $\sim 125$ ranchers, feedlot operators and others connected to the beef cattle industry at the 2020 Southwest Beef Symposium in Amarillo, Texas, where initial rancher perceptions of the three strategies were collected. Cattle producers $(n=36)$ from 26 counties across seven states completed the CAP's "baseline" survey (Elias et al., in review). In response to a question about which topic of the project would be most immediately applicable to their operation, about a quarter indicated that precision ranching technology is most applicable, another quarter selected range finishing in the Southwest and other supply chain options, and another quarter chose the overall integrated approach of the CAP as most applicable. Ten percent of respondents indicated that Spanish/heritage breed cattle would be most applicable. We will compare baseline data with surveys at the end of the 5-year project to detect changes in perceptions about the strategies.

In partnership with the knowledge co-production/extension and research teams, the Asombro Institute for Science Education in New Mexico and the BlueSTEM Agri-Learning Center in Oklahoma have developed lessons and teacher trainings to increase science literacy, advance knowledge about difficult decision-making technology in agriculture, and garner feedback about the strategies under investigation from the agricultural professionals of tomorrow. The integration of K-12 activities into the other components of the CAP emphasizes collaboration, interdisciplinary thinking, and strong communication skills (Bestelmeyer et al., 2015).

In the first year of the project, the education team developed a 1-h classroom lesson and a field trip activity to introduce lower elementary students to Raramuri Criollo (https://asombro. org/wp-content/uploads/Criollo.pdf). Lessons were based on the Sustainable Southwest Beef CAP project and aligned with the Next Generation Science Standards (NGSS), making them relevant to teachers in New Mexico and 19 other states using these standards. Lessons were developed and pilot tested with more than 200 2nd and 3rd grade students in the fall 2020 semester.

School closings in the spring 2020 semester halted classroom lessons, field trips, and teacher trainings. The education team therefore pivoted toward developing an interactive learning experience that could be done by students learning from home. "Solving the Beef" (https://asombro.org/solvingthebeef/) is a game that encourages players in competing teams to develop creative solutions for sustainable beef production and marketing given a set of scenarios and constraints. It is built around engineering design principles from NGSS. Though Solving the Beef was developed as an adaptation to social distancing, it can also be played in a traditional classroom or after-school setting. The game will be expanded by adding additional scenarios as results from the Southwest Beef CAP are published. Moreover, the game will allow the education team to collect ideas from students - the producers and consumers of tomorrow - to feed back to the research component of the project.

\section{ASSESSING AND COMMUNICATING TRADEOFFS}

In addition to peer-reviewed and popular press articles, an interactive repository is being built to house and communicate the integrated knowledge developed by the Sustainable Southwest Beef CAP. The "Western Beef Knowledge System" is being designed to aid decision-making around beef production and consumption, with geographicallyspecific information for producers about the potential benefits and drawbacks of adopting the strategies under investigation, and for consumers seeking locally-tailored guidance on how they can purchase beef that aligns with their stated values. We have also developed short factsheets for use by regional planners and other policy makers, as they evaluate incentives for adoption of the strategies and understand the inter-regional effects of alternative beef supply chains (https://southwestbeef.org/factsheets).

Ultimately, our goal is to apply new, integrated knowledge to advance sustainability of US beef production. Adoption of animal genetics suited to a hotter, drier climate, precision technologies that provide affordable and timely information for ranch management, and alternative marketing options all have potential to improve economic, environmental, and societal outcomes. However, when making significant changes in an agricultural system, full consideration of the regions pericoupled through production is necessary to achieve desired outcomes. With our boundary-spanning approach, we aim to illuminate these inter-regional connections, and identify viable pathways to improve sustainability for beef producers, beef consumers, and the rangelands cherished by Americans nationwide. 


\section{AUTHOR CONTRIBUTIONS}

All authors contributed equally to the ideas in this article. SS was lead writer with contributions from, and editing by, AFC, $\mathrm{BB}, \mathrm{JS}, \mathrm{RE}, \mathrm{DA}, \mathrm{CR}$, and MMu. MMc created artwork for Figure 1.

\section{FUNDING}

The Sustainable Southwest Beef Coordinated Agricultural Project was funded by the USDA National Institute of Food and Agriculture, Agriculture and Food Research Initiative's Sustainable Agricultural Systems (SAS) program. Grant \#2019-69012-29853. This research was also a contribution from the Long-Term Agroecosystem Research (LTAR)

\section{REFERENCES}

Anderson, D. M., Estell, R. E., Gonzalez, A. L., Cibils, A. F., and Torell, L. A. (2015). Criollo cattle: heritage genetics for arid landscapes. Rangelands 37, 62-67. doi: 10.1016/j.rala.2015.01.006

Atkins, R. (2020). New Mexico Cattle Ranchers Busy Due to COVID-19. KRQE. Available online at: https://www.krqe.com/health/coronavirus-new-mexico/ new-mexico-cattle-ranchers-busy-due-to-covid-19/ (accessed July 22, 2020).

Baddock, M. C., Zobeck, T. M., Van Pelt, R. S., and Fredrickson, E. L. (2011). Dust emissions from undisturbed and disturbed, crusted playa surfaces: cattle trampling effects. Aeolian Res. 3, 31-41. doi: 10.1016/j.aeolia.201 1.03.007

Barnes, M. K. (2011). Low-input grassfed livestock production in the American West: case studies of ecological, economic, and social resilience. Rangelands 33, 31-40. doi: 10.2111/1551-501X-33.2.31

Bednarek, A. T., Wyborn, C., Cvitanovic, C., Meyer, R., Colvin, R. M., Addison, P. F. E., et al. (2018). Boundary spanning at the science-policy interface: the practitioners' perspectives. Sustainabil. Sci. 13, 1175-1183. doi: 10.1007/s11625-018-0550-9

Bestelmeyer, B. T., Peters, D. P., Archer, S. R., Browning, D. M., Okin, G. S., Schooley, R. L., et al. (2018). The grassland-shrubland regime shift in the Southwestern United States: misconceptions and their implications for management. BioScience 68, 678-690. doi: 10.1093/biosci/ biy065

Bestelmeyer, S. V., Elser, M. M., Spellman, K. V., Sparrow, E. B., Haan-Amato, S. S., and Keener, A. (2015). Collaboration, interdisciplinary thinking, and communication: new approaches to K-12 ecology education. Front. Ecol. Environ. 13, 37-43. doi: 10.1890/140130

Blank, S. C., Saitone, T. L., and Sexton, R. J. (2016). Calf and yearling prices in the western United States: Spatial, quality, and temporal factors in satellite video auctions. J. Agric. Resource Econ. 41, 458-480. doi: 10.22004/ag.econ.246175

Briske, D. D., Joyce, L. A., Polley, H. W., Brown, J. R., Wolter, K., Morgan, J. A., et al. (2015). Climate-change adaptation on rangelands: linking regional exposure with diverse adaptive capacity. Front. Ecol. Environ. 13, 249-256. doi: 10.1890/140266

Buhnerkempe, M. G., Grear, D. A., Portacci, K., Miller, R. S., Lombard, J. E., and Webb, C. T. (2013). A national-scale picture of US cattle movements obtained from interstate certificate of veterinary inspection data. Prev. Vet. Med. 112, 318-329. doi: 10.1016/j.prevetmed.2013.08.002

Capper, J. L. (2011). The environmental impact of beef production in the United States: 1977 compared with 2007. J. Anim. Sci. 89, 4249-4261. doi: $10.2527 /$ jas.2010-3784

Casey, K. D., Bicudo, J. R., Schmidt, D. R., Singh, A., Gay, S. W., Gates, R. S., et al. (2006). "Air quality and emissions from livestock and poultry production/waste management systems," in Animal Agriculture and the Environment National Center for Manure and Animal Waste Management White Papers, eds. J. M. network. LTAR is supported by the United States Department of Agriculture.

\section{ACKNOWLEDGMENTS}

Many thanks to Dr. Jack Liu for sharing his expertise for our pericoupling analysis. Thanks also to Dr. David Anderson of Texas A\&M for providing data on interstate cattle movements into Texas and inspected by the Texas Animal Health Commission, as discussed in the Supplementary Information.

\section{SUPPLEMENTARY MATERIAL}

The Supplementary Material for this article can be found online at: https://www.frontiersin.org/articles/10.3389/fsufs. 2020.00114/full\#supplementary-material

Rice, D. F. Caldwell, and F. J. Humenik (St. Joseph, MI: American Society of Agricultural and Biological Engineers), 1-40.

Clutton-Brock, J. (1989). "Introduction," in The Walking Larder: Patterns of Domestication, Pastoralism, and Predation, ed. J. Clutton-Brock (London: Unwin Hyman).

da Silva, R. F. B., Batistella, M., Palmieri, R., Dou, Y., and Millington, J. D. (2019). Eco-certification protocols as mechanisms to foster sustainable environmental practices in telecoupled systems. For. Policy Econ. 105, 52-63. doi: 10.1016/j.forpol.2019.05.016

Dimitri, C., Effland, A. B., and Conklin, N. C. (2005). The 20th Century Transformation of US Agriculture and Farm Policy. Washington, DC: US Department of Agriculture, Economic Research Service.

Emmert, M. (2020). As COVID-19 Pandemic Rocks Meatpacking Industry, Iowans Turn to Local Farmers to Buy Meat. Des Moines, IA: Des Moines Register.

Enyinnaya, J. C. (2016). A Case Study of the Economics of Criollo Cattle Production in the Deserts of Southern New Mexico. Las Cruces, NM: New Mexico State University.

Estell, R. E., Havstad, K. M., Cibils, A. F., Fredrickson, E. L., Anderson, D. M., Schrader, T. S., et al. (2012). Increasing shrub use by livestock in a world with less grass. Rangel. Ecol. Manag. 65, 553-562. doi: 10.2111/REM-D-11-00124.1

Food Marketing Institute (2017). Power of Meat: An in-Depth Look at Meat Through the Shoppers' Eyes. Washington, DC: North American Meat Institute.

Gershunov, A., Rajagopalan, B., Overpeck, J., Guirguis, K., Cayan, D., Hughes, M., et al. (2013). "Future climate: projected extremes," in Assessment of Climate Change in the Southwest United States (Washington, DC: Island Press; Springer), 126-147. doi: 10.5822/978-1-61091-484-0_7

Gottschalk, A. (2007). "The impacts of the US corn/ethanol policy on the US cattle industry," in Proceedings, The Range Beef Cow Symposium XX, (Fort Collins, Colorado).

Guerrero, B., Amosson, S., and McCollum, T. (2013). The impact of the beef industry in the Southern Ogallala Region. College Station, Texas: Texas A\&M Agrilife Extension, AG-001.

Havstad, K. M., Brown, J. R., Estell, R., Elias, E., Rango, A., and Steele, C. (2018). Vulnerabilities of Southwestern US Rangeland-based animal agriculture to climate change. Clim. Change 148, 371-386. doi: 10.1007/s10584-016-1834-7

Heitschmidt, R. K., and Taylor, C. A. (1991). "Livestock production," in Grazing: an Ecological Perspective, eds. R. K. Heitschmidt and J. W. Stuth (Portland: Timber Press), 161-177.

Hendrickson, M. K. (2020). Covid lays bare the brittleness of a concentrated and consolidated food system. Agric. Hum. Values. 12:1-12. doi: 10.1007/s10460-020-10092-y

Hobbs, J. E. (2020). Food supply chains during the COVID-19 pandemic. Can. J. Agric. Econ. Revue Can. D'agroeconomie. 1-6. doi: 10.1111/cjag. 12237

Holechek, J. L. (1992). Financial benefits of range management practices in the Chihuahuan Desert. Rangelands 14, 279-284. 
Hunt, L. P., Petty, S., Cowley, R., Fisher, A., Ash, A. J., and MacDonald, N. (2007). Factors affecting the management of cattle grazing distribution in northern Australia: preliminary observations on the effect of paddock size and water points. Rangel. J. 29, 169-179. doi: 10.1071/RJ07029

Johnson, R., and Becker, G. S. (2009). Livestock Marketing and Competition Issues. CRS Report for Congress 2009. Washington, DC: US Government Printing Office.

Kleinman, P. J. A., Spiegal, S., Rigby, J. R., Goslee, S., Baker, J., Bestelmeyer, B. T., et al. (2018). Advancing sustainable intensification of U.S. agriculture through long-term research. J. Environ. Qual. 47, 1412-1425. doi: 10.2134/jeq2018.05.0171

Liu, J. (2017). Integration across a metacoupled world. Ecol. Soc. 22:29. doi: 10.5751/ES-09830-220429

Martínez-Cordova, Y., García-Galicia, I. A., and Rodríguez-Almeida, F. A. (2014). "Características de la carne de ganado Criollo de Chihuahua, Angus $\times$ Criollo y Hereford $\times$ Angus finalizados en corral," in XLI Reunión de la Asociación Mexicana para la Producción Animal y Seguridad Alimentaria A.C. (AMPA) y VII Reunión Nacional de Sistemas Agro y Silvopastoriles (Mérida), 5.

Mathews, K. H., and Johnson, R. J. (2013). Alternative Beef Production Systems: Issues and Implications. USDA ERS. LDPM-218-01.

McGuire, V. L. (2017). Water-Level and Recoverable Water in Storage Changes, High Plains Aquifer, Predevelopment to 2015 and 2013-15. Scientific Investigations Report 2017-5040. US Geological Survey.

McIntosh, M. M., Cibils, A. F., Estell, R. E., Soto-Navarro, S. A., Gonzalez, A. L., Nyamuryekung,'E., et al. (2018). "Weight gain and behavior of Raramuri Criollo versus Corriente steers developed on Chihuahuan Desert rangeland," in 71st Annual Society for Range Management Meeting Abstracts (Sparks, NV: Society for Range Management).

McIntosh, M. M., Holechek, J. L., Spiegal, S. A., Cibils, A. F., and Estell, R. E. (2019). Long-term declining trends in Chihuahuan Desert forage production in relation to precipitation and ambient temperature. Rangel. Ecol. Manag. 72, 976-87. doi: 10.1016/j.rama.2019.06.002

Nagus, C. (2020). As beef shortages take place due to COVID-19 outbreak, local rancher sees sales surge. KMOV4. Available online at: https://www.krqe.com/ health/coronavirus-new-mexico/new-mexico-cattle-ranchers-busy-due-tocovid-19/ (accessed July 22, 2020).

Nash, M. S., Jackson, E., and Whitford, W. G. (2003). Soil microtopography on grazing gradients in Chihuahuan Desert grasslands. J. Arid Environ. 55, 181-192. doi: 10.1016/S0140-1963(02)00251-3

National Research Council (2010). Toward Sustainable Agricultural Systems in the 21st Century. Washington, DC: The National Academies Press.

Neethirajan, S. (2017). Recent advances in wearable sensors for animal health management. Sens. Bio-Sens. Res. 12, 15-29. doi: 10.1016/j.sbsr.2016.11.004

Nyamuryekung'e, S., Cibils, A. F., Estell, R. E., Gonzalez, A. L., Cano, D. E., and Spiegal, S. (2017). "Behavior of Raramuri Criollo vs. Angus-crossbred cows in relation to desert summer ambient heat conditions," in 70th Annual Society for Range Management Meeting Abstracts (St. George, UT: Society for Range Management).

Owens, M. K., Launchbaugh, K. L., and Holloway, J. W. (1991). Pasture characteristics affecting spatial distribution of utilization by cattle in mixed brush communities. J. Range Manag. 44, 118-123. doi: 10.2307/40 02308

Peel, D. S., Dustin, A., Randy, B., Kenneth, B., Don, C., Amy, H., et al. (2020). Economic Damages to the U.S. Beef Cattle Industry Due to COVID-19. Oklahoma Cooperative Extension Service Available online at: https://extension.okstate.edu/coronavirus/media/beef-economic-damagesfull-report-covid-19.pdf (accessed May 26, 2020).

Peinetti, H. R., Fredrickson, E. L., Peters, D. P., Cibils, A. F., Roacho-Estrada, J. O., and Laliberte, A. S. (2011). Foraging behavior of heritage versus recently introduced herbivores on desert landscapes of the American Southwest. Ecosphere 2:art57. doi: 10.1890/ES11-00021.1
Polley, H. W., Briske, D. D., Morgan, J. A., Wolter, K., Bailey, D. W., and Brown, J. R. (2013). Climate change and North American rangelands: trends, projections, and implications. Rangeland Ecol. Manag. 66, 493-511. doi: 10.2111/REM-D-12-00068.1

Ramankutty, N., Mehrabi, Z., Waha, K., Jarvis, L., Kremen, C., Herrero, M., et al. (2018). Trends in global agricultural land use: implications for environmental health and food security. Annu. Rev. Plant Biol. 69, 789-815. doi: 10.1146/annurev-arplant-042817-040256

Rotz, C. A., Asem-Hiablie, S., Place, S., and Thoma, G. (2019). Environmental footprints of beef cattle production in the United States. Agric. Syst. 169, 1-13. doi: 10.1016/j.agsy.2018.11.005

Spiegal, S., Bestelmeyer, B. T., Archer, D. W., Augustine, D. J., Boughton, E. H., Boughton, R. K., et al. (2018). Evaluating strategies for sustainable intensification of US agriculture through the Long-Term Agroecosystem Research Network. Environ. Res. Lett. 13:034031. doi: 10.1088/1748-9326/aaa779

Spiegal, S., Estell, R. E., Cibils, A. F., James, D. K., Peinetti, H. R., Browning, D. M., et al. (2019). Seasonal divergence of landscape use by heritage and conventional cattle on desert rangeland. Rangeland Ecol. Manag. 72, 590-601. doi: 10.1016/j.rama.2019.02.008

Texas A\&M (2020). COVID-19 “The Texas A\&M system responds - episode 7," in The Age of the Coronavirus, Chancellor John Sharp Seeks to Answer the Question: "Where's the beef?" May 20, 2020 Interview of Dr. David Anderson. College Station, TX: The Texas A\&M University System.

Tonsor, G. T., Schroeder, T. C., Pennings, J. M. E., and Mintert, J. (2009). Consumer valuations of beef steak food safety enhancement in Canada, Japan, Mexico, and the United States. Can. J. Agric. Econ. Revue Canadienne D’agroeconomie 57, 395-416. doi: 10.1111/j.1744-7976.2009.01158.x

Torell, L. A., Rimbey, N. R., Tanaka, J. A., and Bailey, S. A. (2001). "The lack of a profit motive for ranching: implications for policy analysis," in Proceedings of a Symposium Sponsored by the Western Coordinating Committee. Current Issues in Rangeland Resource Economics, (Kailua-Kona, Hawaii, USA). Available online at: http://www.publiclandsranching.org/htmlres/pdf/ ref_torell_lack_profit_motive.pdf (accessed November 16, 2013).

Torell, L. A., Rimbey, N. R., Tanaka, J. A., Taylor, D. T., and Wulfhorst, J. D. (2014). Ranch level economic impact analysis for public lands: a guide to methods, issues, and applications. J. Rangeland Appl. 1, 1-13.

USDA-ERS (2016). Farm Income and Wealth Statistics. Available online at: https:// www.ers.usda.gov/data-products/farm-income-and-wealth-statistics/chartsand-maps-of-us-farm-balance-sheet-data.aspx (accessed July 22, 2020).

USDA-NASS (2020). Beef Cow Inventory by State, Survey 2010-2020. Available online at: https:/quickstats.nass.usda.gov/results/C28763F7-8229-331B93E9-AB82F81216E8 (accessed May 24, 2020).

USGCRP (2017). "Climate science special report: fourth national climate assessment," Volume I. eds. D. J. Wuebbles, D. W. Fahey, K. A. Hibbard, B. C. Dokken, B., Stewart, and T. K. Maycock (Washington, DC: Global Change Research Program).

Conflict of Interest: The authors declare that the research was conducted in the absence of any commercial or financial relationships that could be construed as a potential conflict of interest.

Copyright (C) 2020 Spiegal, Cibils, Bestelmeyer, Steiner, Estell, Archer, Auvermann, Bestelmeyer, Boucheron, Cao, Cox, Devlin, Duff, Ehlers, Elias, Gifford, Gonzalez, Holland, Jennings, Marshall, McCracken, McIntosh, Miller, Musumba, Paulin, Place, Redd, Rotz, Tolle and Waterhouse. This is an open-access article distributed under the terms of the Creative Commons Attribution License (CC BY). The use, distribution or reproduction in other forums is permitted, provided the original author(s) and the copyright owner(s) are credited and that the original publication in this journal is cited, in accordance with accepted academic practice. No use, distribution or reproduction is permitted which does not comply with these terms. 